University of South Carolina

Scholar Commons

$1-27-2000$

\title{
Comparison of TOVS-derived Land Surface Variables with Ground Observations
}

Venkataraman Lakshmi

University of South Carolina - Columbia, vlakshmi@geol.sc.edu

Joel Susskind

Follow this and additional works at: https://scholarcommons.sc.edu/geol_facpub

Part of the Earth Sciences Commons

\section{Publication Info}

Published in Journal of Geophysical Research, Volume 105, Issue D2, 2000, pages 2179-2190. Lakshmi, V. \& Susskind, J. (2000). Comparison of TOVS-derived land surface variables with ground observations. Journal of Geophysical Research, 105 (D2), 2179-2190. (C) Journal of Geophysical Research 2000, American Geophysical Union

This Article is brought to you by the Earth, Ocean and Environment, School of the at Scholar Commons. It has been accepted for inclusion in Faculty Publications by an authorized administrator of Scholar Commons. For more information, please contact digres@mailbox.sc.edu. 


\title{
Comparison of TOVS-derived land surface variables with ground observations
}

\author{
Venkataraman Lakshmi \\ Department of Geological Sciences, University of South Carolina, Columbia \\ Joel Susskind \\ Laboratory for Atmospheres, NASA Goddard Space Flight Center, Greenbelt, Maryland
}

\begin{abstract}
The Tiros Operational Vertical Sounder (TOVS) Pathfinder Path A retrieved surface skin temperature, surface air temperatures, and surface specific humidity are compared with data obtained from three large-scale field campaigns: the First ISLSCP (International Satellite Land Surface Climatology Project) Field Experiment (FIFE), the Hydrologic Atmospheric Pilot Experiment (HAPEX) in the Sahel, and the Boreal Ecosystem-Atmosphere Study (BOREAS). The long-term estimates of surface skin temperatures, surface air temperatures, and surface vapor pressure were unbiased, and the standard deviations of the errors were about $4^{\circ} \mathrm{C}, 3.5^{\circ} \mathrm{C}$, and $3.5 \mathrm{mbar}$, respectively. The monthly mean variables obtained from the TOVS data at four times of the day (corresponding to the AM and PM overpass for each of two satellites) exhibited realistic diurnal and seasonal cycles when compared with corresponding ground observations.
\end{abstract}

\section{Introduction}

Continental scale hydrological modeling has been limited by the lack of ground observations that are needed as input. Ground observations suffer from two drawbacks. Firstly, ground observation networks are expensive to maintain for extended periods of time. Secondly, ground observations are point observations and thereby do not capture the spatial variability over large regions. Satellite data overcome these two drawbacks. Most of the satellite sensors are in orbit for multiple years and have 2-4 times of day repeat observations of the land surface. This paper carries out direct comparisons of satellite and ground-based observations of land surface variables of surface temperature, air temperature, and vapor pressure.

This study follows along the lines of previous studies [Sugita and Brutsaert, 1993; Kalluni and Dubayah, 1995] which compared a few days of satellite-estimated skin temperatures with field observations. In our study, we focus on a longer time period of comparisons (than those mentioned above) to achieve a confidence in our statistical characterization of the differences between TOVS-retrieved data and ground observations. Surface skin temperature comparisons is emphasized in this paper. In recent years, there have been several field campaigns that have provided us with improved data sets for these comparisons. The satellite data used in this study is from the TOVS Pathfinder Path A data set [Susskind et al., 1997]. This data set (TOVS Pathfinder Path A) has been produced using a consistent algorithm and validated extensively [Susskind et al., 1997; Lakshmi and Susskind, 1998; Anyamba and Susskind, 1998]. Our comparisons were carried out over large areas $\left(1^{\circ} \times 1^{\circ}\right)$ and long time periods (a year or more). The comparisons were made in three contrasting areas: the tall grass prairie of Kansas, United States (FIFE), the boundary of the desert, bush, and savanna in the Sahel, Niger in West

This paper is not subject to U.S. copyright. Published in 2000 by the American Geophysical Union.

Paper number 1999JD900921.
Africa (HAPEX-Sahel), and the boreal forest in Canada (BOREAS).

\section{Data and Methods}

\subsection{Satellite Data}

The Tiros Operational Vertical Sounder (TOVS) consists of the HIRS2 (High-Resolution Infrared Sounder), the MSU (microwave sounding unit), and the SSU (Stratospheric Sounding Unit). The HIRS2 has 20 channels in the infrared, visible, and near-infrared region $(3.74-14.96 \mu \mathrm{m})$, and the MSU consists of four channels in the $50 \mathrm{GHz}$ range $(50.3$, $53.74,54.96$, and $57.95 \mathrm{GHz}$ ). TOVS is flown on NOAA satellites [Kidwell, 1995], and one can obtain from each satellite (some years have two different satellites, Table 1), twice a day (ascending and descending orbits), global fields of temperature and moisture profiles of the atmosphere, surface skin and air temperatures, as well as estimates of ozone amount in the atmosphere and cloud and precipitation variables [Susskind et al., 1997]. TOVS has been flown since November 1978 and the processed data will soon exist for the entire period 1979-1999. The Pathfinder Path A products also include the local time of observation.

The TOVS Pathfinder Path A physically based retrieval system uses the Goddard Earth Observing System (GEOS) $\left(4^{\circ} \times\right.$ $5^{\circ}$ ) general circulation model 6 hour forecast as the first guess for temperature and moisture profiles. The retrieval algorithm then modifies these profiles and surface skin temperatures so that the radiances computed from the solution best match the cloud-corrected radiances for partially cloudy and cloud-free fields of view. A $2 \times 2$ array of HIRS 2 spots $(60 \mathrm{~km} \times 60 \mathrm{~km}$ at nadir) and the closest MSU spot are used to reconstruct the clear-sky (upwelling) radiances, i.e., the radiance in the cloudfree portions of the scene [Susskind et al., 1984; Susskind et al., 1997|. The radiometric surface temperatures are obtained directly using the infrared channels by correcting for atmospheric attenuation [Susskind et al., 1984]. The emissivities 
Table 1. List of Satellites and Nominal Overpass Times for TOVS

\begin{tabular}{|c|c|c|}
\hline Satellite & $\begin{array}{c}\text { Nominal } \\
\text { Overpass } \\
\text { Time }\end{array}$ & Period \\
\hline Tiros N & $300 \mathrm{am} / \mathrm{pm}$ & December 1978 to December 1979 \\
\hline NOAA 6 & $730 \mathrm{am} / \mathrm{pm}$ & July 1979 to May $1982^{*}$ \\
\hline NOAA 7 & $230 \mathrm{am} / \mathrm{pm}$ & July 1981 to May $1982^{*}$ \\
\hline NOAA 9 & $230 \mathrm{am} / \mathrm{pm}$ & January 1985 to December 1986 \\
\hline NOAA 10 & $730 \mathrm{am} / \mathrm{pm}$ & December 1986 to July 1991 \\
\hline NOAA 11 & $130 \mathrm{am} / \mathrm{pm}$ & November 1988 to December 1994 \\
\hline & $730 \mathrm{am} / \mathrm{pm}$ & August 1997 to present \\
\hline NOAA 12 & $730 \mathrm{am} / \mathrm{pm}$ & July 1991 to December 1998 \\
\hline NOAA 14 & $230 \mathrm{am} / \mathrm{pm}$ & January 1995 to present \\
\hline NOAA 15 & $730 \mathrm{am} / \mathrm{pm}$ & June 1998 to present \\
\hline
\end{tabular}

Asterisk, presently processed. NOAA 6 ends in March 1983 and NOAA 7 extends till December 1984 . Read $300 \mathrm{am} / \mathrm{pm}$ as 0300/1500 LT.

assumed over land for the HIRS2 channel $8\left(900 \mathrm{~cm}^{-1}\right)$ is 0.95 and 0.85 for channels 18 and $19\left(2500 \mathrm{~cm}^{-1}\right)$. The temperature and humidity profiles are determined using an iterative process that varies the initial profiles smoothly in height in a manner that is consistent with the channel observations. This is achieved by calculating radiative transfer through the atmosphere to determine the radiances at the satellite. Surface air temperature and the specific humidity initial guesses are obtained by extrapolating the GCM first-guess profiles of air temperature and humidity to the surface pressure level. The single value of retrieved land surface and atmospheric variables are interpreted as averages over the cloud-free portions of the scene. In general, retrievals can be performed in up to $80 \%$ fractional cloudiness [Susskind et al., 1997].

The TOVS Pathfinder Path A data are available as a gridded $1^{\circ} \times 1^{\circ}$ (latitude by longitude) product for both the morning and the afternoon overpasses for each satellite. The data are also available in pentad (five day averages) and monthly averaged forms. The afternoon orbit near 1330 drifts considerably in time. The TOVS data used in this paper are from the NOAA 10, 11, 12, and 14 satellites (nominal local nadir observation time at the equator of $0730 / 1930,0130 / 1330,0730 /$ 1930, and 0230/1430 LT, respectively).

\subsection{Field Observations}

This section describes three measurement campaigns that have collected high spatial and temporal resolution data which are compared with corresponding satellite-retrieved variables.

2.2.1. FIFE. The First ISLSCP (International Satellite Land Surface Climatology Project) Field Experiment (FIFE) was conducted near Manhattan, Kansas, between 1987 and 1989. One of the objectives of this campaign was to understand the relationship between the satellite-measured values of land surface variables and the ground observations [Sellers and Hall, 1992].

The FIFE study area was $15 \mathrm{~km} \times 15 \mathrm{~km}$, predominantly covered by tall grass prairie and surrounded by grassland and agriculture. The surface skin temperature was measured by nadir-looking infrared thermometers (IRT), while the air temperature and the surface relative humidity were measured by dry and wet bulb thermometers. These instruments were located in automated meteorological stations (AMS). The experiment itself was conducted as a series of intensive field campaigns for shorter periods of time in the summer and fall of 1987 and 1989. In these periods, half hourly heat flux, surface and air temperature and humidity measurements, detailed observations of the boundary layer using radiosondes, and daily soil moisture measurements were carried out at 30 sites. The automated meteorological stations collected data continuously every half hour between May 30, 1987 and November 10,1989 . This provides nearly a 2.5 year data set that was used in this study. The site-averaged data [Betts and Ball, 1998] have been used in this paper. The IRTs were located in fenced enclosures with no grazing. Therefore the IRT recorded surface temperature is cooler than bare soil (due to transpiration by grass) and has a diurnal and seasonal range that is modulated by the vegetation.

2.2.2. HAPEX-Sahel. The Hydrologic Atmospheric Pilot Experiment in Sahel (HAPEX-Sahel) was conducted in western Niger, West Africa, over a 3-4 year period with an 8 week intensive observation period (IOP) from August 25 to October 1,1992 . The area was a $1^{\circ} \times 1^{\circ}$ region $(\sim 110 \mathrm{~km} \times 110 \mathrm{~km})$ extending from $2^{\circ}$ to $3^{\circ} \mathrm{E}$ and $13^{\circ}$ to $14^{\circ} \mathrm{N}$. The measurements were carried out with a temporal frequency of 1 hour for surface air temperature and relative humidity and a $10 \mathrm{~min}$ frequency for surface skin temperature during the 8 week IOP. The landscape consisted of various landcover types: tiger bush, millet, and fallow areas. The main purpose of the campaign was to obtain a better understanding of the changes in the atmospheric circulation due to changes in the land surface conditions in the Sahel from year to year [Prince et al., 1995; Goutorbe et al., 1994]. The most important feature of this campaign was its larger area $(110 \mathrm{~km} \times 110 \mathrm{~km})$ compared to FIFE $(15 \mathrm{~km} \times 15 \mathrm{~km})$. This allows for the field data to be interpreted in the context of output from general circulation models (GCMs) as well as providing a better match with data retrieved from satellite sensors.

The data collection was organized spatially into three supersites: the eastern central, western central, and southern. The values of hourly surface air temperature and relative humidity for 1992 were used in this study measured by using dry bulb and wet bulb thermometers, hygrometers, respectively, at the climate stations. The surface skin temperature data for the intensive observation period comes from many sources: the Institute of Hydrology infrared thermometer data for the fallow, millet, and tiger bush regions (central west and southern supersite); the data over millet soil in the central east supersite; data over the millet and grassland region; data over the herbacious grass-sparse layer, and the data from the climate station (which also collected air temperature and relative humidity data).

2.2.3. BOREAS. The Boreal Ecosystem-Atmosphere Study (BOREAS) was carried out over a $1000 \mathrm{~km} \times 1000 \mathrm{~km}$ study region in Canada. The two major study areas in this campaign were placed at the northern and southern ecotones in order to determine the effect of the different controlling factors that were responsible for the various land-atmosphere interactions in these regions. The northern and the southern study areas (NSA and SSA) were $500 \mathrm{~km}$ apart. The NSA was located $98^{\circ} 30^{\prime} \mathrm{W}, 56^{\circ} 00^{\prime} \mathrm{N}$ and the SSA was located $104^{\circ} 45^{\prime} \mathrm{W}$ and $53^{\circ} 45^{\prime} \mathrm{N}$. There were a total of 10 towers that measure fluxes of water, energy, and $\mathrm{CO}_{2}$ and other atmospheric and land surface variables such as surface skin temperature, air temperature, and relative humidity near the surface in the two areas. The towers were placed in areas of different vegetation type such as black spruce, jack pine, and aspen, which reflect the surface type of the area surrounding the tower. The observations at these towers began in December 1993 and ended in 


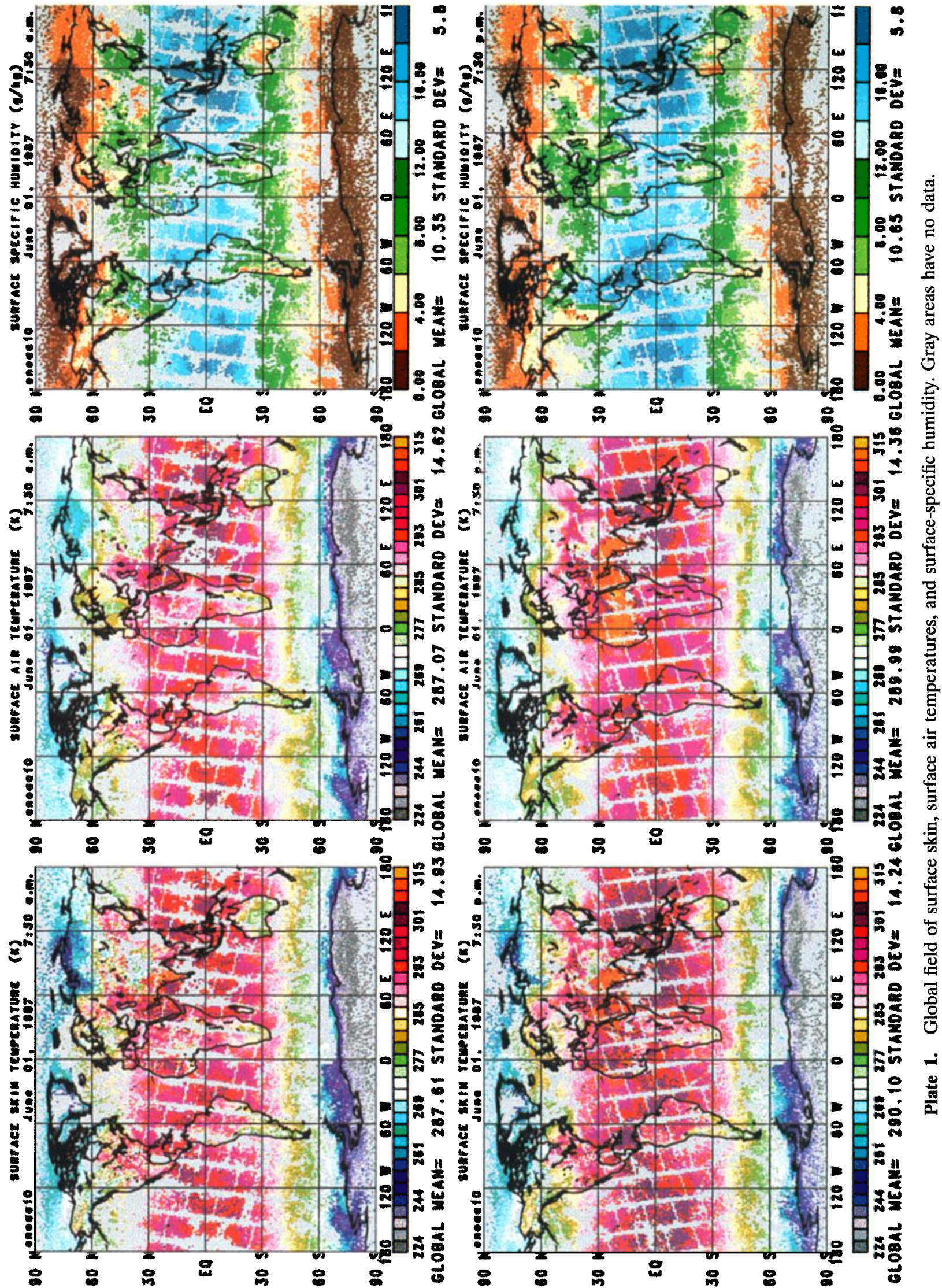


November/December 1996 and were carried out at $15 \mathrm{~min}$ intervals to obtain a 3 year observation period for the region. The observations are made from towers at a height of $2 \mathrm{~m}$ (for the air temperature and the relative humidity) and a nadirlooking infrared thermometer for the surface skin temperature. The objectives of these observations and the BOREAS experiment campaign are to bridge various spatial scales among physical processes connected with leaf biochemistry which can be applied to atmospheric general circulation models (AGCMs) and other carbon cycle models [Sellers et al., 1997].

\subsection{Methodology}

The surface skin temperature $\left(T_{s}\right)$, surface air temperature $\left(T_{a}\right)$, and the surface vapor pressure $\left(e_{a}\right)$ from the field campaigns were compared with the TOVS data for the $1^{\circ} \times 1^{\circ}$ grid box which includes the field site. The field observations at the closest time of the satellite overpass were compared with the satellite data. The difference in time between the satellite observations and the ground observation was at most $15 \mathrm{~min}$ in the case of FIFE (half hourly observations), $30 \mathrm{~min}$ in the case of HAPEX-Sahel surface air temperature, and relative humidity (hourly observations) and 5 min for surface skin temperatures (10 min observations) and $7.5 \mathrm{~min}$ at BOREAS (15 min observations). The satellite observation local time varies considerably over the scan line. Taking the exact satellite local observation time into account was significant, because surface skin temperature changes quite rapidly, especially during the sunrise and early morning hours. In the case of HAPEX-Sahel the campaign area covers a $1^{\circ} \times 1^{\circ}$ grid, and therefore comparisons with the $1^{\circ} \times 1^{\circ}$ gridded TOVS data are justified. The FIFE campaign area was $15 \mathrm{~km} \times 15 \mathrm{~km}$. In the case of BOREAS the field observations were made at 10 flux towers in the study area. The observations from each flux tower were compared with the corresponding $1^{\circ} \times 1^{\circ}$ grid box in which it was located. The flux towers were placed in areas that represent the surrounding location (usually represent $\leq 1 \mathrm{~km}^{2}$ ), so the measurement is characteristic of that surrounding region.

The surface vapor pressure was computed from the TOVS data by using the surface specific humidity (which is a standard
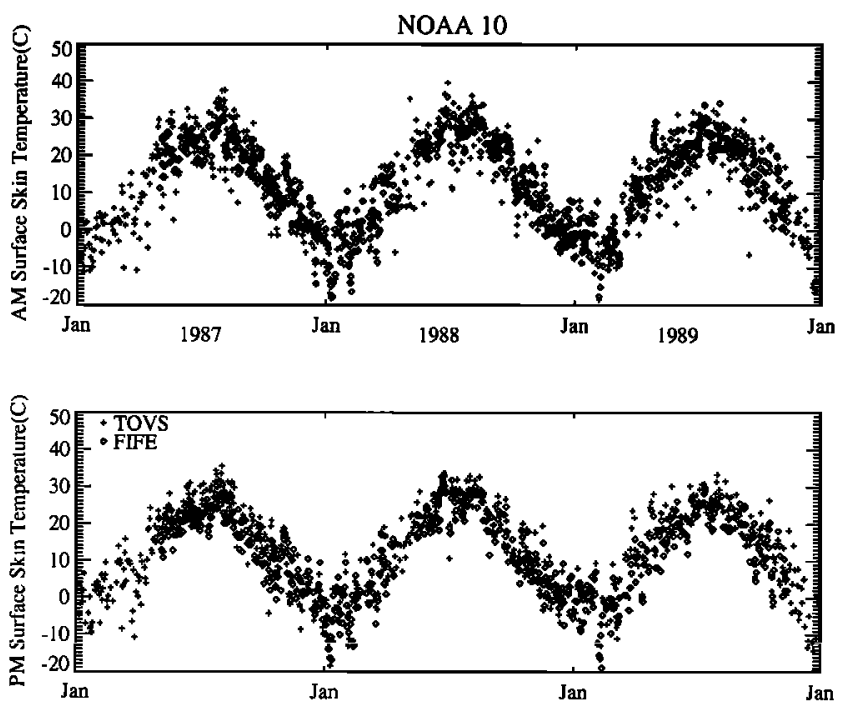

Figure 1. Time series of surface skin temperatures (C): FIFE and NOAA 10.
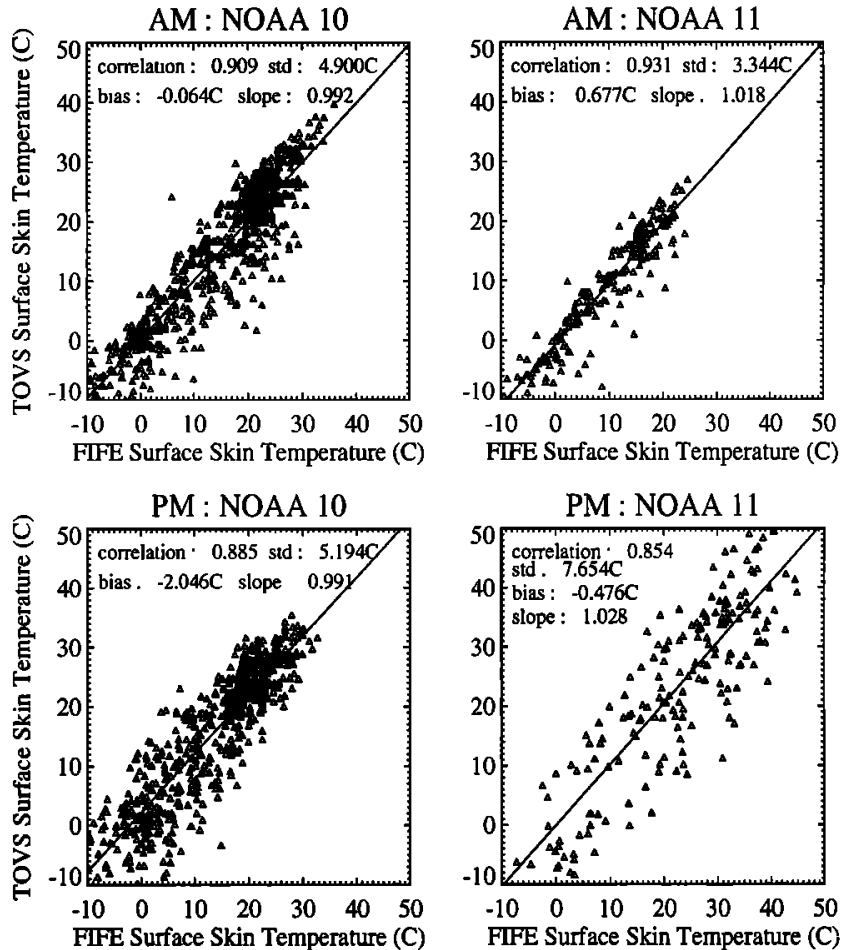

Figure 2. Scatterplot of surface skin temperatures (C): FIFE versus TOVS. The mean difference over all observations (bias = IRT - TOVS) is indicated on the figures as well as the slope of the regression line fit, the correlation, and standard deviation of the difference between FIFE and TOVS data. A positive value of bias means that on the average the FIFEobserved surface temperatures were warmer than the TOVSretrieved data.

TOVS data product) and the GEOS-GCM grid point surface pressure. The surface vapor pressure for the field observations at FIFE, HAPEX-Sahel, and BOREAS was computed using the observed relative humidity, surface air temperature and/or wet bulb temperatures.

Comparisons of the field observations and the TOVS retrievals were performed for four individual times a day in periods when NOAA 11 data existed to supplement either NOAA 10 or NOAA 12 . Mean monthly diurnal curves (i.e. a diurnal cycle based on half-hourly observations for a month) were constructed using the field observations, and the TOVS data were superimposed on these curves for each of the 4 times of the day (averaged over the month) for which observations were available.

\section{Results}

Examples of global fields of surface skin temperature, surface air temperature, and surface specific humidity for a single day (June 1,1987$)$ are shown in Plate 1 . The plate is from the NOAA 10 satellite $(\sim 0730 / 1930$ LT). Actual local times will vary by more than \pm 1 hour across a scan line, and nadir times vary from 0730 with distance from the equator. Areas in which no data exists are shown in gray. Part of this is due to orbit gaps and calibration cycles, which occur for three consecutive scan lines in a block of 40 lines. Other gaps occur in places where no retrievals could be produced, most often because of excessive cloudiness or precipitation. The 1930 LT surface skin temper- 
Table 2. Daily Comparisons in Surface Fields for Surface Skin Temperature

\begin{tabular}{|c|c|c|c|c|c|c|c|c|}
\hline Variable & Experiment & Satellite & $\begin{array}{c}\text { Overpass } \\
\text { Time }\end{array}$ & $n$ & s.d. & Corr & Slope & Bias \\
\hline \multirow[t]{12}{*}{$T_{s}$} & FIFE & NOAA 11 & $130 \mathrm{am}$ & 200 & $3.3^{\circ} \mathrm{C}$ & 0.93 & 1.02 & $0.7^{\circ} \mathrm{C}$ \\
\hline & & & $130 \mathrm{pm}$ & 180 & $7.7^{\circ} \mathrm{C}$ & 0.85 & 1.04 & -0.5 \\
\hline & & NOAA 10 & $730 \mathrm{am}$ & 552 & $4.9^{\circ} \mathrm{C}$ & 0.91 & 0.99 & $-0.1^{\circ} \mathrm{C}$ \\
\hline & & & $730 \mathrm{pm}$ & 533 & $5.2^{\circ} \mathrm{C}$ & 0.89 & 0.99 & $-2.0^{\circ} \mathrm{C}$ \\
\hline & HAPEX & NOAA 11 & $130 \mathrm{am}$ & 18 & $2.8^{\circ} \mathrm{C}$ & 0.25 & 0.57 & $1.6^{\circ} \mathrm{C}$ \\
\hline & & & $130 \mathrm{pm}$ & 21 & $4.1^{\circ} \mathrm{C}$ & 0.62 & 0.71 & $0.6^{\circ} \mathrm{C}$ \\
\hline & & NOAA 12 & $730 \mathrm{am}$ & 14 & $3.0^{\circ} \mathrm{C}$ & 0.63 & 1.0 & $3.2^{\circ} \mathrm{C}$ \\
\hline & & & $730 \mathrm{pm}$ & 27 & $1.7^{\circ} \mathrm{C}$ & 0.81 & 1.09 & $0.5^{\circ} \mathrm{C}$ \\
\hline & BOREAS & NOAA $11 / 14$ & $230 \mathrm{am}$ & 5640 & $5.8^{\circ} \mathrm{C}$ & 0.93 & 0.95 & $1.5^{\circ} \mathrm{C}$ \\
\hline & & & $230 \mathrm{pm}$ & 5555 & $5.2^{\circ} \mathrm{C}$ & 0.94 & 0.95 & $0.6^{\circ} \mathrm{C}$ \\
\hline & & NOAA 12 & $730 \mathrm{am}$ & 5423 & $6.2^{\circ} \mathrm{C}$ & 0.93 & 0.96 & $0.6^{\circ} \mathrm{C}$ \\
\hline & & & $730 \mathrm{pm}$ & 5605 & $5.2^{\circ} \mathrm{C}$ & 0.94 & 0.92 & $0.9^{\circ} \mathrm{C}$ \\
\hline
\end{tabular}

atures were warmer than the morning surface skin temperatures in the equatorial and subtropical regions along most lines of the longitude. The same was true for surface air temperatures, which were similar but not identical to surface skin temperatures. This was reflected in the global means (computed using a latitudinal area weighting) for both the surface skin and the surface air temperatures. Over arid areas, 1930 surface air temperatures were considerably warmer than 1930 surface skin temperatures, because the maximum air temperature occurred later in the day than that of skin temperature. The surface specific humidity did not show as strong a diurnal difference as the temperatures (both skin and air). The surface specific humidity in the $30^{\circ} \mathrm{N}-30^{\circ} \mathrm{S}$ region varied between 12 and $17 \mathrm{~g} / \mathrm{kg}$.

\subsection{Daily Comparisons}

3.1.1. FIFE. The comparisons of daily morning and afternoon surface skin temperatures over the 2.5 year period determined from TOVS at the FIFE site, corresponding to the
NOAA 10 (equatorial overpass time 0730/1930) are shown in Figure 1. There were more TOVS observations than IRT (infrared thermometer) data because FIFE first began in June 1987 , and many days were missing in the subsequent periods. There was a clear annual cycle to the morning and afternoon PM surface skin temperature and the TOVS retrievals captured this seasonal cycle very well (Figure 1). The vertical spread of surface skin temperatures is due to the day-to-day variability of the surface temperature and the time of observation of the TOVS not being exactly the same on subsequent days (this is a minor effect).

Figure 2 gives scatter diagrams of the TOVS and FIFE data for days in common for the morning and afternoon overpasses of NOAA 10 and NOAA 11 . On the average, there was a slight underestimation of the mean IRT surface skin temperature by the TOVS surface skin temperature for the NOAA $1000 \mathrm{LT}$ overpass $\left(+0.06^{\circ} \mathrm{C}\right)$. This underestimation was greater in the case of IRT surface temperatures greater than $10^{\circ} \mathrm{C}$. There
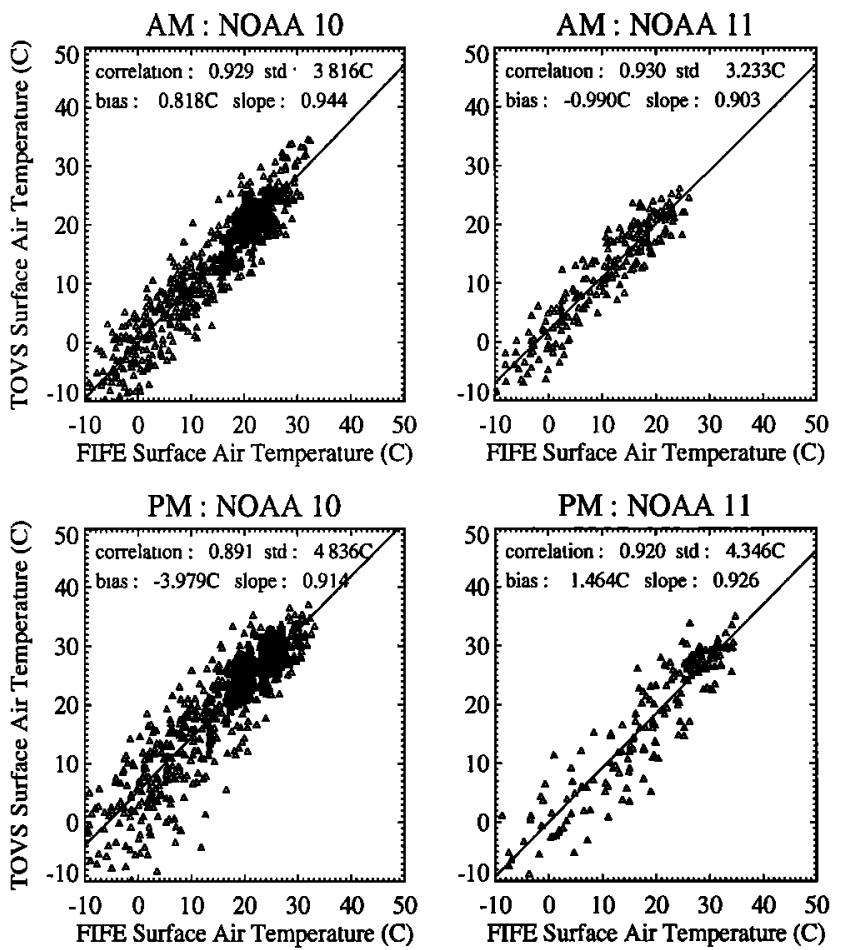
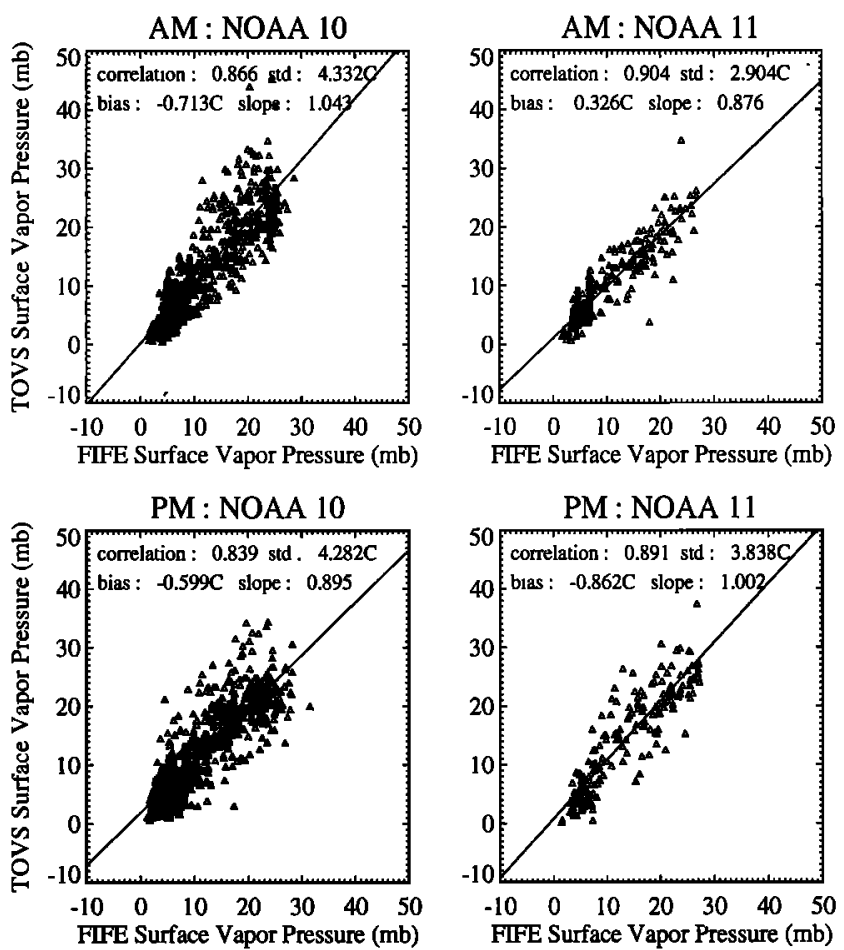

Figure 3. Surface air temperatures (C): FIFE versus TOVS. 
Table 3. Daily Comparisons in Surface Fields for Surface Air Temperature

\begin{tabular}{|c|c|c|c|c|c|c|c|c|}
\hline Variable & Experiment & Satellite & $\begin{array}{l}\text { Overpass } \\
\text { Time }\end{array}$ & $n$ & s.d. & Corr & Slope & Bias \\
\hline \multirow[t]{12}{*}{$T_{s}$} & \multirow[t]{4}{*}{ FIFE } & \multirow[t]{2}{*}{ NOAA 11} & $130 \mathrm{am}$ & 211 & $3.2^{\circ} \mathrm{C}$ & 0.93 & 0.90 & $-1.0^{\circ} \mathrm{C}$ \\
\hline & & & $130 \mathrm{pm}$ & 180 & $4.3^{\circ} \mathrm{C}$ & 0.92 & 0.93 & $1.5^{\circ} \mathrm{C}$ \\
\hline & & \multirow[t]{2}{*}{ NOAA 10} & $730 \mathrm{am}$ & 564 & $3.8^{\circ} \mathrm{C}$ & 0.93 & 0.94 & $0.8^{\circ} \mathrm{C}$ \\
\hline & & & $730 \mathrm{pm}$ & 562 & $4.8^{\circ} \mathrm{C}$ & 0.89 & 0.91 & $-4.0^{\circ} \mathrm{C}$ \\
\hline & \multirow[t]{4}{*}{ HAPEX } & \multirow[t]{2}{*}{ NOAA 11} & $130 \mathrm{am}$ & 164 & $4.3^{\circ} \mathrm{C}$ & 0.50 & 0.47 & $2.1^{\circ} \mathrm{C}$ \\
\hline & & & $130 \mathrm{pm}$ & 182 & $3.4^{\circ} \mathrm{C}$ & 0.64 & 0.62 & $3.3^{\circ} \mathrm{C}$ \\
\hline & & \multirow[t]{2}{*}{ NOAA 12} & $730 \mathrm{am}$ & 149 & $3.9^{\circ} \mathrm{C}$ & 0.65 & 0.50 & $2.9^{\circ} \mathrm{C}$ \\
\hline & & & $730 \mathrm{pm}$ & 171 & $3.3^{\circ} \mathrm{C}$ & 0.71 & 0.61 & $-0.7^{\circ} \mathrm{C}$ \\
\hline & \multirow[t]{4}{*}{ BOREAS } & \multirow{2}{*}{ NOAA $11 / 14$} & $230 \mathrm{am}$ & 6099 & $5.1^{\circ} \mathrm{C}$ & 0.95 & 0.91 & $-0.7^{\circ} \mathrm{C}$ \\
\hline & & & $230 \mathrm{pm}$ & 5989 & $5.2^{\circ} \mathrm{C}$ & 0.94 & 0.95 & $-1.8^{\circ} \mathrm{C}$ \\
\hline & & \multirow[t]{2}{*}{ NOAA 12} & $730 \mathrm{am}$ & 5846 & $5.4^{\circ} \mathrm{C}$ & 0.95 & 0.94 & $-1.5^{\circ} \mathrm{C}$ \\
\hline & & & $730 \mathrm{pm}$ & 6048 & $4.9^{\circ} \mathrm{C}$ & 0.95 & 0.88 & $-1.4^{\circ} \mathrm{C}$ \\
\hline
\end{tabular}

were also a few cases of overestimation of the FIFE surface skin temperatures between $20^{\circ} \mathrm{C}$ and $30^{\circ} \mathrm{C}$ by the TOVS surface skin temperatures for the morning overpass. There were at least four cases of low surface temperatures as reported by the IRT at FIFE during the summer months, as can be seen from Figure 1. This underestimate is $15^{\circ} \mathrm{C}$ in some of the cases. The IRTs at FIFE were mostly placed in grassland sites. During the warm afternoons and evenings when the bare soil temperature was much higher, the IRT reported the canopy temperature that tends to be cooler because of evapotranspiration. This could be the reason why we observe many IRT data points on the bottom edge (of the band of points) for the NOAA 2200 LT overpass. The average bias (as seen in Table 2) shows that the IRT was $2.0^{\circ} \mathrm{C}$ cooler than the TOVS surface temperature, which is consistent with our interpretation. The slope of the least squares fit line to the scatterplot of TOVS versus IRT data was 0.99 for the NOAA 10 morning overpass and 0.992 for the NOAA 10 afternoon overpass, which were close to complete agreement (1.0). The correlation between the TOVS and the FIFE data was 0.91 for the NOAA 10 morning and 0.87 for the NOAA 10 afternoon overpasses, and the standard deviation of the difference was $4.9^{\circ} \mathrm{C}$ and $5.2^{\circ} \mathrm{C}$ for the NOAA 10 morning and afternoon overpasses, respectively (Table 2).

In the case of NOAA 11 , there was an underestimation (bias $=0.68^{\circ} \mathrm{C}$ ) for the morning overpass and an overestimation (bias $=-0.48^{\circ} \mathrm{C}$ ) for the afternoon overpass. The slopes of the regression lines are close to unity, and the correlations are high (0.93 and 0.85 , respectively). The standard deviations for the NOAA 11 morning and afternoon surface skin temper- atures were $3.3^{\circ} \mathrm{C}$ and $7.1^{\circ} \mathrm{C}$, respectively. The larger standard deviation for the NOAA 11 afternoon case was due to the greater variability of the TOVS surface skin temperatures during the early afternoon hours near $1330 \mathrm{LT}$.

The results for the comparison of the surface air temperature from TOVS and FIFE are shown as a scatterplot in Figure 3. The standard deviation of the differences were $3.8^{\circ} \mathrm{C}$ and $4.8^{\circ} \mathrm{C}$ for the morning and afternoon satellite overpasses of NOAA 10 and $3.2^{\circ} \mathrm{C}$ and $4.3^{\circ} \mathrm{C}$ for the NOAA 11 morning and afternoon overpasses. The respective biases were $0.8^{\circ} \mathrm{C}$ and $-4.0^{\circ} \mathrm{C}$, and $-1.0^{\circ} \mathrm{C}$ and $1.5^{\circ} \mathrm{C}$, the correlations were 0.93 and 0.89 , and 0.93 and 0.93 , while the slopes were 0.94 and 0.91 and 0.93 and 0.92 for the morning and afternoon overpasses of NOAA 10 and morning and afternoon overpasses of NOAA 11 , respectively. The striking difference between comparisons of the surface skin temperature and the surface air temperature (Figures 2 and 3 ) was the tighter grouping of the points around the regression line for the surface air temperature, which was reflected in the higher correlation and the lower standard deviations. This might be a result of air temperature varying more slowly in space and time than the skin temperatures and sampling differences in space and time being less significant.

The corresponding results for the vapor pressure are shown in Figure 4, with standard deviation differences of 4.3 and 4.3 $\mathrm{mb}$, and 2.9 and 3.9 , biases of -0.7 and $-0.6 \mathrm{mb}$, and 0.3 and $-0.9 \mathrm{mb}$, correlations of 0.87 and 0.84 , and 0.9 and 0.9 , and slopes of 1.0 and 0.9 , and 0.9 and 1.0 for the morning and afternoon overpasses of NOAA 10 and morning and afternoon overpasses of NOAA 11, respectively. The range of TOVS

Table 4. Daily Comparisons in Surface Fields for Surface Vapor Pressure

\begin{tabular}{|c|c|c|c|c|c|c|c|c|}
\hline Variable & Experiment & Satellite & $\begin{array}{c}\text { Overpass } \\
\text { Time }\end{array}$ & $n$ & s.d. & Corr & Slope & Bias \\
\hline \multirow{12}{*}{$e_{a}$} & \multirow[t]{4}{*}{ FIFE } & \multirow[t]{2}{*}{ NOAA 11} & $130 \mathrm{am}$ & 208 & $2.9 \mathrm{mbar}$ & 0.90 & 0.88 & $0.3 \mathrm{mbar}$ \\
\hline & & & $130 \mathrm{pm}$ & 182 & 3.8mbar & 0.89 & 1.00 & $-0.9 \mathrm{mbar}$ \\
\hline & & \multirow[t]{2}{*}{ NOAA 10} & $730 \mathrm{am}$ & 569 & $4.3 \mathrm{mbar}$ & 0.87 & 1.00 & $-0.7 \mathrm{mbar}$ \\
\hline & & & $730 \mathrm{pm}$ & 562 & $4.3 \mathrm{mbar}$ & 0.84 & 0.89 & $-0.6 \mathrm{mbar}$ \\
\hline & \multirow{4}{*}{ HAPEX } & \multirow[t]{2}{*}{ NOAA 11} & $130 \mathrm{am}$ & 169 & $3.9 \mathrm{mbar}$ & 0.93 & 0.75 & $1.0 \mathrm{mbar}$ \\
\hline & & & $130 \mathrm{pm}$ & 138 & $2.9 \mathrm{mbar}$ & 0.95 & 0.89 & $-2.0 \mathrm{mbar}$ \\
\hline & & \multirow[t]{2}{*}{ NOAA 12} & $730 \mathrm{am}$ & 120 & $4.0 \mathrm{mbar}$ & 0.92 & 0.80 & $-0.2 \mathrm{mbar}$ \\
\hline & & & $730 \mathrm{pm}$ & 157 & $3.6 \mathrm{mbar}$ & 0.94 & 0.76 & $-1.5 \mathrm{mbar}$ \\
\hline & \multirow[t]{4}{*}{ BOREAS } & \multirow[t]{2}{*}{ NOAA $11 / 14$} & $230 \mathrm{am}$ & 5911 & $2.3 \mathrm{mbar}$ & 0.89 & 0.92 & $-0.2 \mathrm{mbar}$ \\
\hline & & & $230 \mathrm{pm}$ & 5760 & $2.7 \mathrm{mbar}$ & 0.83 & 0.93 & $-0.6 \mathrm{mbar}$ \\
\hline & & \multirow[t]{2}{*}{ NOAA 12} & $730 \mathrm{am}$ & 5700 & $2.6 \mathrm{mbar}$ & 0.86 & 0.97 & $-0.7 \mathrm{mbar}$ \\
\hline & & & $730 \mathrm{pm}$ & 5798 & $2.1 \mathrm{mbar}$ & 0.89 & 0.88 & $0.0 \mathrm{mbar}$ \\
\hline
\end{tabular}


vapor pressures was smaller than that of surface measurements at FIFE. This is the case for the afternoon overpass of NOAA 10 and morning overpass of NOAA 11 . The maximum overestimation and underestimation in the case of the NOAA 11 overpasses is less than $10 \mathrm{mb}$. There is a $25-30$ mbar range in the vapor pressure that is captured by the TOVS data.

Tables 2-4 summarize the comparison statistics for the variables shown in Figures 1-4. In general, the standard deviation of the differences between TOVS and FIFE was lower for the NOAA 11 morning overpass compared to the afternoon overpass.

3.1.2. HAPEX-Sahel. The comparisons for the surface skin temperatures in HAPEX-Sahel are shown in Figure 5 as a line of best fit for the data points.

The standard deviation of the difference between TOVS and HAPEX-Sahel surface skin temperature was a maximum at the afternoon overpass of NOAA 11 (equatorial overpass time of 1330 LT), as was found with comparison of TOVS and FIFE data. The local meteorological conditions were such that the maximum gradient in surface skin temperatures are at 1330 LT in both cases. The magnitudes of the standard deviation of the differences are around $3.5^{\circ} \mathrm{C}$. The correlation between the TOVS and the HAPEX-Sahel data was low for the NOAA 11 0130 LT overpass $(0.25)$, in which there was very little variability of the HAPEX skin temperature measurements.

Correlations in other cases, with larger temporal variabilities, were $0.62,0.63$, and 0.81 for NOAA 11 1330, NOAA 12 0730 , and NOAA 120730 , respectively. The bias for this time (NOAA 110130 overpass) was also larger than the corresponding FIFE case (around $1.6^{\circ} \mathrm{C}$ compared to $0.68^{\circ} \mathrm{C}$ at
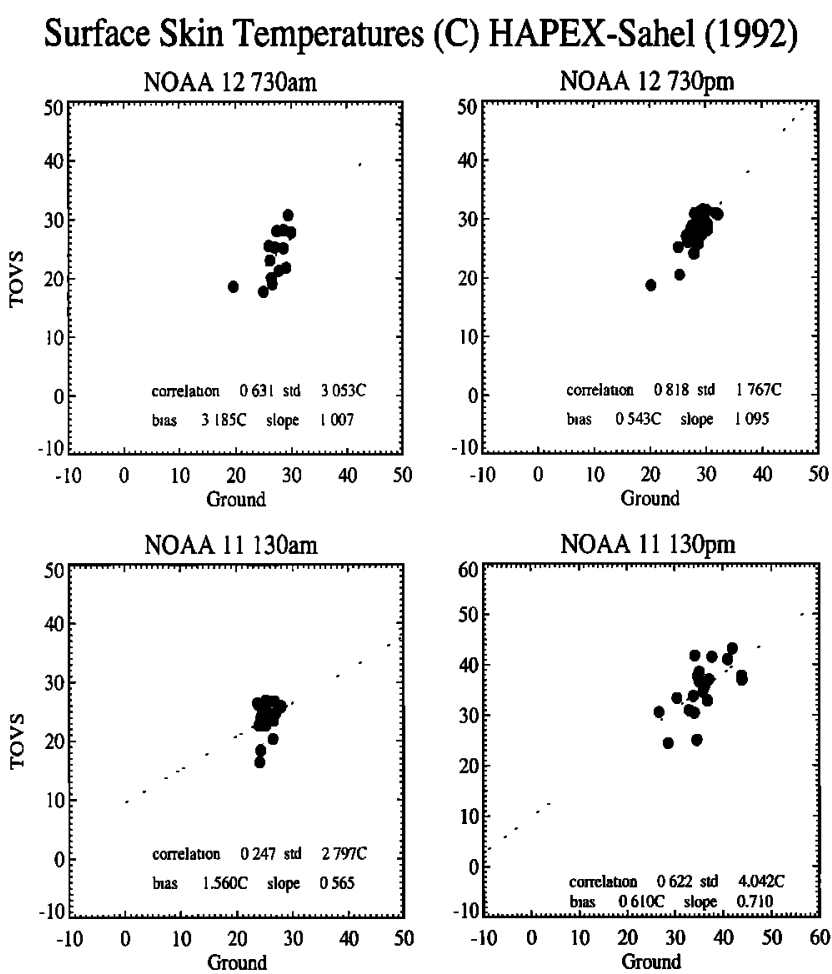

Figure 5. Surface skin temperatures: HAPEX versus TOVS. Dots denote the points obtained from averaging surface skin temperature measurements at eight sites during the intensive observation period (IOP) between August 25 and October 1, 1992.
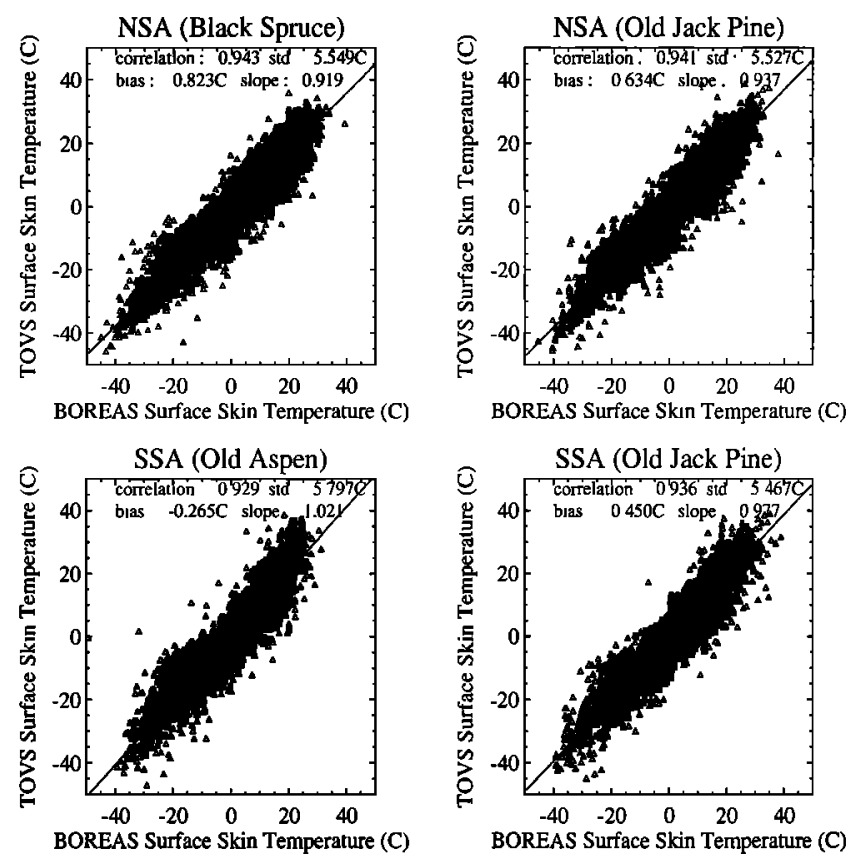

Figure 6. BOREAS surface skin temperature versus TOVS surface skin temperature for four different sites: (a) northern study area (NSA) black spruce, (b) NSA old jack pine, (c) southern study area (SSA) old aspen, and (d) SSA old jack pine.

FIFE), and the slopes were significantly different from 1.0 for the case of NOAA 110130 and 1330 (0.57 and 0.71, respectively). The plots show that the TOVS data were biased with respect to the ground data, especially at 0130 and 0730 . We would expect the ground collection of surface skin temperatures to be biased toward regions of lesser vegetation amount, and the satellite data considered equal contributions from all regions. The vegetation temperatures will generally be cooler than bare soil temperatures due to transpiration. This is consistent with the sign of the differences. The differences could also be attributed to the surface heterogeneity that existed at the HAPEX-Sahel site. The number of observations of surface skin temperatures were restricted to the IOP and ranged between 14 and 27 observations depending on the satellite overpass. The standard deviation of the difference in the case of surface air temperatures and the surface vapor pressure were comparable to the counterparts in the FIFE comparisons.

Statistics for surface air temperature and specific humidity are included in Tables 2-4. The biases in the surface air temperature for HAPEX-Sahel were about $1.0^{\circ}-1.5^{\circ} \mathrm{C}$ higher than the corresponding values in FIFE. The correlations range from 0.47 to 0.62 , and the slopes were lower $(0.50-0.71)$. The standard deviation of the differences range between $3.3^{\circ}$ and $4.3^{\circ} \mathrm{C}$. These are the same values as in FIFE. The slopes are lesser than the optimal values of unity, which means that the range of the TOVS retrieved surface air temperatures were lesser than the observed range at HAPEX-Sahel. The number of observations were comparable to FIFE for the NOAA 11 overpasses; however, in the case of NOAA 12 the number of observations was lower (around 150) compared to FIFE NOAA 10 (around 560). This is because the data used in these comparisons were for 1 year (1992) only for HAPEX-Sahel compared to multiple years (1987-1989) for FIFE. The differences between the HAPEX-Sahel and FIFE statistics on vapor pres- 

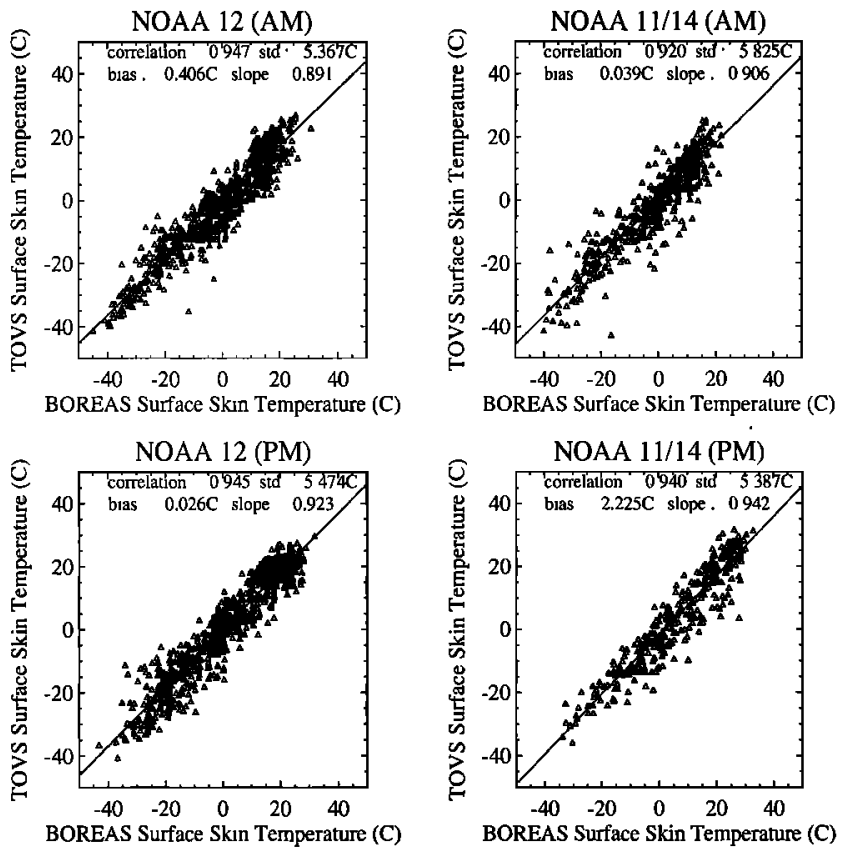

Figure 7. Scatterplot of BOREAS versus TOVS surface skin temperature for NOAA 12 morning and afternoon and NOAA 11 and 14 for morning and afternoon for the BOREAS NSA black spruce vegetation cover.

sure are less than that for surface temperature described above. The slopes of the regression lines between the satelliteretrieved and the HAPEX-Sahel-observed vapor pressure is close to unity; the correlation coefficients were in the range of $0.75-0.90$.

3.1.3. BOREAS. The comparison of the TOVS-retrieved surface skin temperature, surface air temperature, and surface vapor pressure to the corresponding observations at BOREAS are summarized in Tables 2,3 , and 4, respectively. The number of observations over which the comparisons are carried out is larger by an order of magnitude in the case of BOREAS as compared to FIFE and by 2 orders of magnitude as compared to HAPEX-Sahel.

The bias in the surface skin temperature (IRT observationsTOVS retrievals) ranges from $1.5^{\circ} \mathrm{C}$ for the NOAA 11 and NOAA 14 morning overpass to $0.6^{\circ} \mathrm{C}$ for the NOAA 11 and NOAA 14 afternoon and the NOAA 12 morning overpass with the NOAA 12 evening overpass having a bias of $0.9^{\circ} \mathrm{C}$ in between these two values. These values fall within the same range as those seen in FIFE and HAPEX-Sahel. The standard deviations range between $5.2^{\circ} \mathrm{C}$ and $6.2^{\circ} \mathrm{C}$, which are slightly higher than those seen in FIFE and HAPEX-Sahel with the exception of the NOAA 11 afternoon overpass at FIFE, which has a value of $7.7^{\circ} \mathrm{C}$. The correlations between the BOREASobserved and the TOVS-retrieved surface skin temperatures are greater than 0.9 in all the satellite overpasses, and the slopes of the regression lines are close to 1 , indicating a close agreement in the range of the satellite and the ground observations.

The surface vapor pressure comparisons from Table 4 show very good agreements between the satellite-retrieved and the BOREAS-observed values. The biases are all negative ranging from 0.0 to $0.69 \mathrm{mb}$, the correlations are higher than 0.8 , and the slopes range between 0.88 and 0.97 . The values of the standard deviation between the satellite and the ground obser- vations are less than those of FIFE and HAPEX-Sahel. The maximum value of the standard deviation $(2.7 \mathrm{mb})$ is less than the minimum value for the FIFE and the HAPEX-Sahel cases $(2.9 \mathrm{mb})$.

The comparisons between the BOREAS observations and the TOVS-retrieved surface skin temperatures are shown in Figure 6 for four different sites with each panel in the figure containing data from all the satellite overpasses for that site. The comparison statistics in the figure do not indicate any bias with respect to vegetation cover; that is, the values of correlation, bias, standard deviation, and slope for the different sites are quite similar in numerical value. The only exception is the southern study area old aspen vegetation cover site that has a slight negative bias as opposed to the positive biases for all the other cases.

The surface skin temperatures as retrieved from the TOVS and the observations at the BOREAS northern study area with black spruce vegetation cover as shown in Figure 7. The TOVS retrievals correspond to the $1^{\circ} \times 1^{\circ}$ grid box, which contains the flux tower at the BOREAS site. This result is displayed as a function of the overpass times of the NOAA satellites NOAA 12 and NOAA 11 and 14 . The greatest amount of scatter about the $1: 1$ line is seen for NOAA 11 and NOAA 14 morning overpass (0230 LT) at the equator and an early morning overpass (NOAA 12,0730) at the BOREAS site and the least amount of scatter is for NOAA 12 morning overpass. The

\section{Surface Skin Temperature (C)}
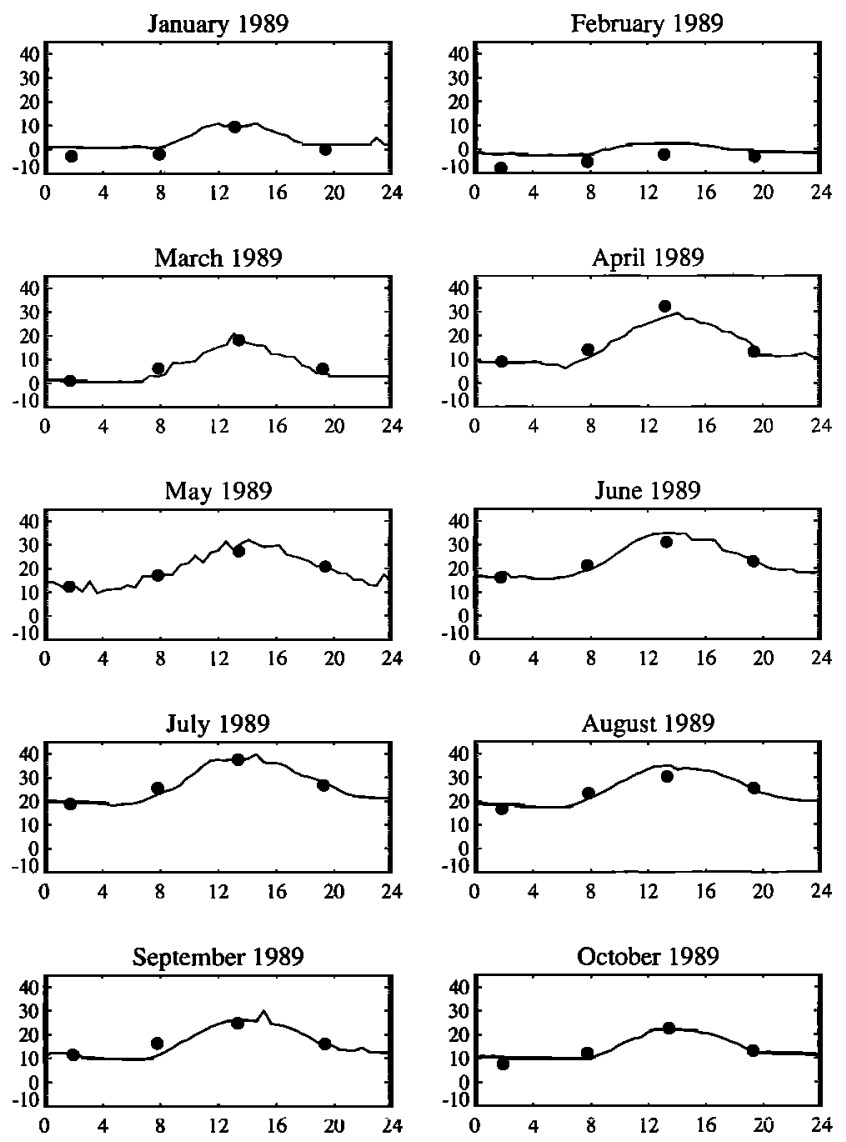

Figure 8. Diurnal variations of surface skin temperatures (C): FIFE versus TOVS. Solid line indicates FIFE observations, and circles are the TOVS retrievals. 
comparisons for this particular site (and for the other nine that are not shown) are similar to the comparisons for the data from all the sites pooled together and displayed in Tables 2,3 , and 4 .

\subsection{Diurnal Cycles}

The mean monthly diurnal variation of the FIFE surface skin temperature for 10 months in 1989 , derived from hourly data, is shown in Figure 8 . The TOVS data are denoted by circles that correspond to the four times of day observations by the NOAA 10 and NOAA 11 satellites. There are some cases when the two do not compare favorably. The NOAA 110130 LT data for February is an example in which the TOVS data underestimated the field observations by almost $3^{\circ} \mathrm{C}$. NOAA 11 also underestimated the surface skin temperature in this month at 1330 LT. The 0730 overpass for March 1989 showed a $5^{\circ} \mathrm{C}$ overestimation with respect to the FIFE diurnal curve. The NOAA 10 (around 1930 LT) data showed the best agreement to the FIFE-observed diumal cycle for all the 10 months.

The comparison of the four times of day TOVS-derived surface air temperature and surface specific humidity with the observations from FIFE is shown in Figures 9 and 10, respectively. The TOVS monthly mean surface air temperature diurnal cycle has a lesser agreement with the FIFE observations as compared to the surface skin temperature. There are large biases in the 1330 (January 1989), 1330 (February 1989), 1330

\section{Surface Air Temperature (C)}
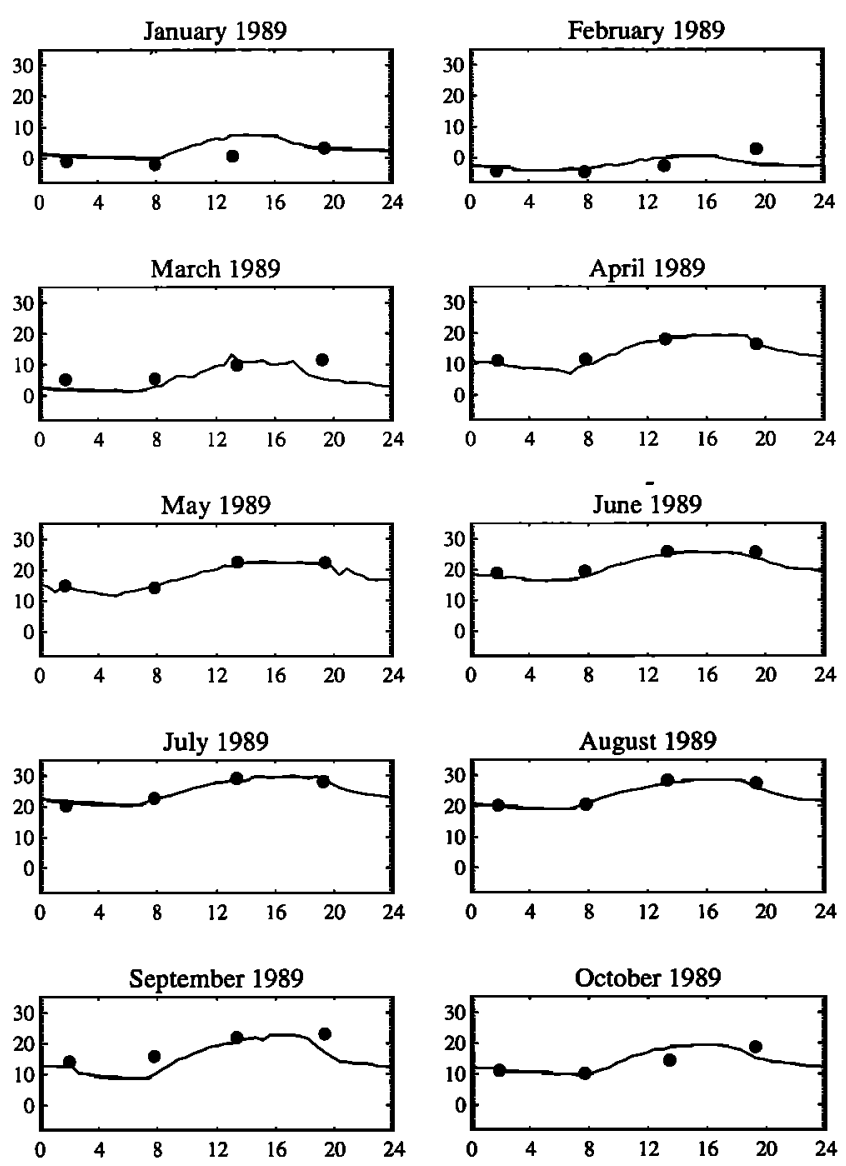

Figure 9. Diurnal variations of surface air temperatures $(C)$ : FIFE versus TOVS. Solid line indicates FIFE observations, and circles are the TOVS retrievals.
Surface Vapor Pressure (mb)
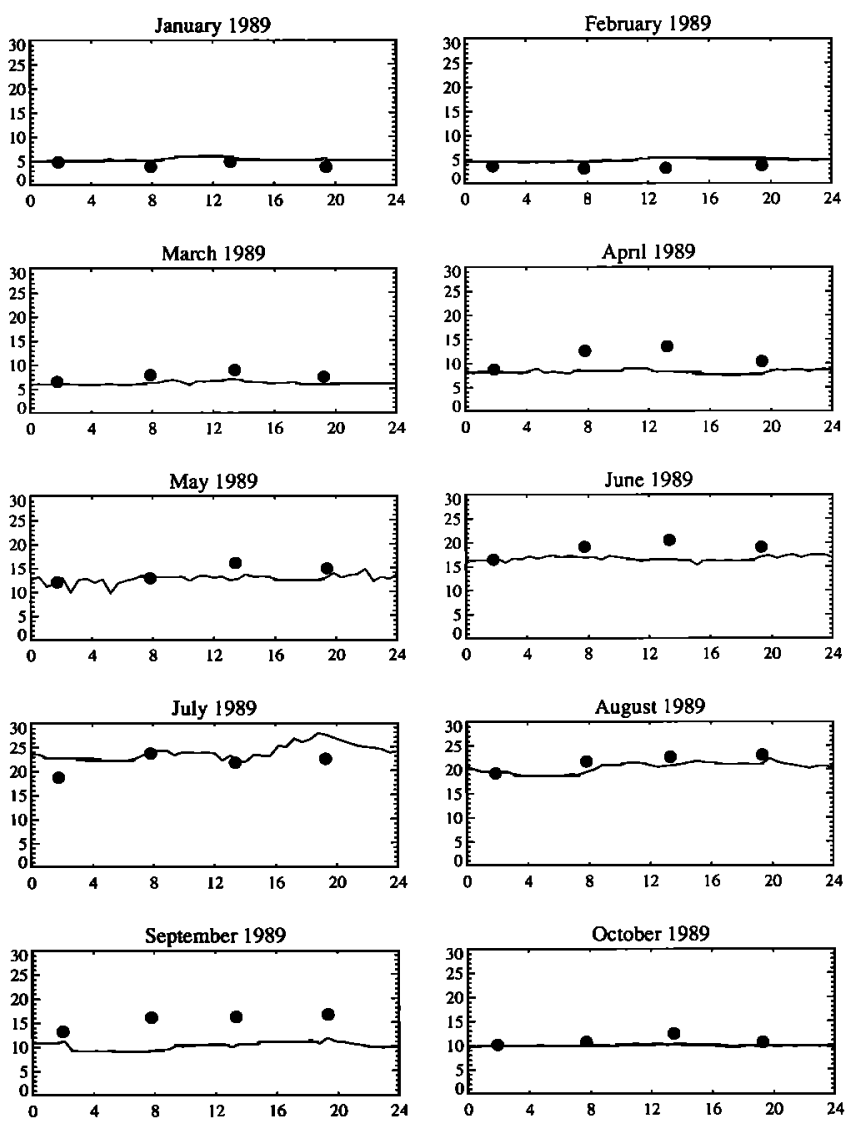

Figure 10. Diurnal variations of surface vapor pressure (mb): FIFE versus TOVS. Solid line indicates FIFE observations, and circles are the TOVS retrievals.

(March 1989), 0730 (September 1989), and 1330 LT (October 1989). These biases are around $5^{\circ}-8^{\circ} \mathrm{C}$. The TOVS-retrieved surface air temperatures show a good agreement with the FIFE monthly mean diurnal cycle for all the months, especially the summer months of April to August 1989. There is a gradual warming between January and July 1989 which is captured very well by the TOVS data. It can also be seen that the surface air temperature monthly mean diurnal cycle has a smaller amplitude $\left(15^{\circ} \mathrm{C}\right)$ compared to a larger amplitude $\left(25^{\circ}-30^{\circ} \mathrm{C}\right)$ for the surface skin temperature.

The surface vapor pressure does not show a strong diurnal cycle like the surface skin and air temperatures, as shown in Figures 8 and 9 . The monthly mean diurnal cycle is mostly flat with an amplitude ranging from 2 to $5 \mathrm{mb}$. In spite of this low magnitude the TOVS retrievals suffer from overestimations for all the overpasses in September 1989, three $(0730,1330$, and 1930 LT) overpasses in April 1989 and two (0730 and 1330 LT) overpasses in June 1989. These overestimations range from 5 to $10 \mathrm{mb}$. The surface vapor pressure shows a slight diurnal cycle with increases at 0730 and 1330 LT vapor pressure compared to the 1330 and $1930 \mathrm{LT}$ values. This is very well pronounced in the April 1989 TOVS retrievals. The agreements between the TOVS surface vapor pressure and the monthly mean diurnal curve from the FIFE ground-observed values is good for the other months. 


\section{Standard Deviations (C)}
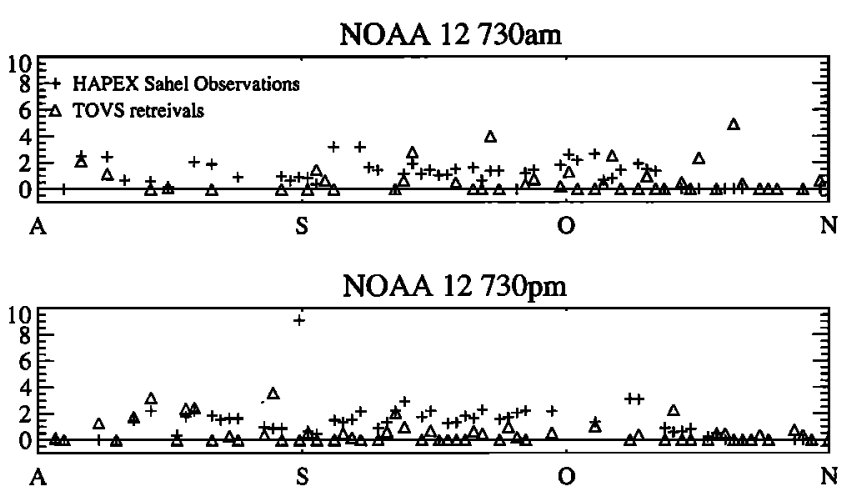

NOAA 11 130am
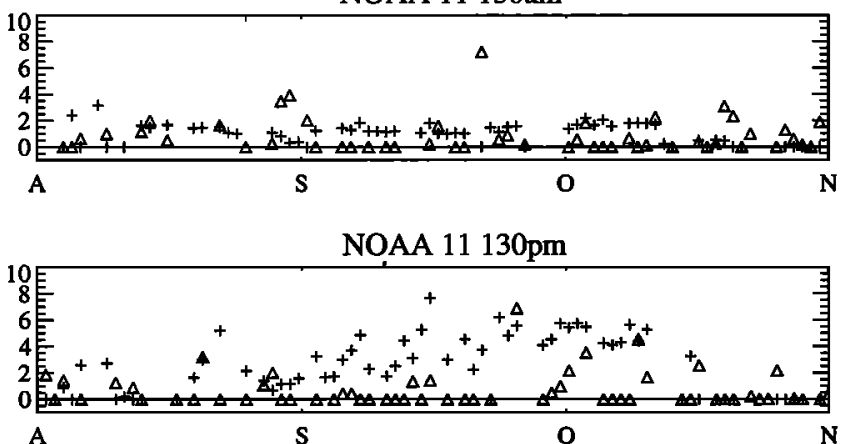

Figure 11. Standard deviations of surface skin temperatures (C): HAPEX versus TOVS.

\subsection{Spatial Heterogeneity}

An important limitation with regard to use of satellite data is their inability to capture small-scale spatial heterogeneity. Satellite observations report an average of temperatures in the field weighted higher to warmer temperatures as a result of the nonlinearity of the Planck blackbody function. In areas with large variability in land surface cover and/or relief, such as HAPEX Sahel, the question of the biases in remote sensing estimates due to nonlinear mixing might arise. The TOVS data are gridded on $1^{\circ} \times 1^{\circ}$ basis globally as an average of all values from all the satellite spots (nominally $60 \mathrm{~km} \times 60 \mathrm{~km}$ ) which fall within this grid. The data also include the spatial standard deviation of the spots in the grid box.

The daily standard deviation of the surface skin temperatures observed in HAPEX-Sahel and reported by TOVS data are shown in Figure 11 for August to November 1992. In the case of TOVS, if only a single retrieval occurred over the $1^{\circ} \times$ $1^{\circ}$ region for the overpass, the standard deviation is zero. The zero standard deviation line is included in the figure. This gives us an idea of the nonzero values of the HAPEX-observed and the TOVS standard deviations.

The HAPEX-Sahel spatial standard deviations are between $0^{\circ}$ and $3^{\circ} \mathrm{C}$, with some values around $4^{\circ} \mathrm{C}$ and one value (NOAA 12 afternoon overpass) of $9^{\circ} \mathrm{C}$. In contrast, the TOVSderived standard deviations are generally smaller, and most of the values are zero (only one observation in a $1^{\circ} \times 1^{\circ}$ box). The standard deviations of the surface skin temperature observations reflect the heterogeneity due to surface processes. The NOAA 11 (equatorial overpass 1330) shows the largest amounts of observed standard deviations (between $2^{\circ} \mathrm{C}$ and $6^{\circ} \mathrm{C}$ ).

\subsection{Seasonal Cycle}

In the case of BOREAS, there are three years of observed data and one can construct seasonal cycles for the ground and the satellite data. Figure 12 shows a comparison of how the satellite and the ground observations of monthly maximum, monthly minimum, and mean surface skin temperatures agree with each other. The satellite retrievals are lower than the ground observations (using the IRT) for the monthly minimum temperature and higher than the ground observations for the monthly maximum surface skin temperatures. These maximum, minimum, and mean surface skin temperatures represent the dynamic range and characteristic for the whole BOREAS region (data from all the 10 stations pooled together) and for all satellite overpasses (all satellites, morning and afternoon overpasses pooled together). The monthly mean values for the ground observations have been calculated using the $15 \mathrm{~min}$ observations at the towers (96 daily observations) and the 4 times of day overpass of the NOAA satellites for the TOVS. The satellite retrievals capture the range in surface skin temperatures which is close to $50^{\circ} \mathrm{C}$. The differences between the satellite and the ground observations of the surface skin temperatures are less than $5^{\circ} \mathrm{C}$ in the maximum and minimum monthly surface skin temperatures and less than $2^{\circ} \mathrm{C}$ in the mean monthly surface skin temperatures (Table 5). For most of the months the difference between the ground and the satellite mean monthly skin temperatures is less than $1^{\circ} \mathrm{C}$. The difference exceeds $2^{\circ} \mathrm{C}$ only rarely (October 1995). The TOVS surface skin temperatures capture the seasonal cycle of the ground observations very well; that is, they have the maxima
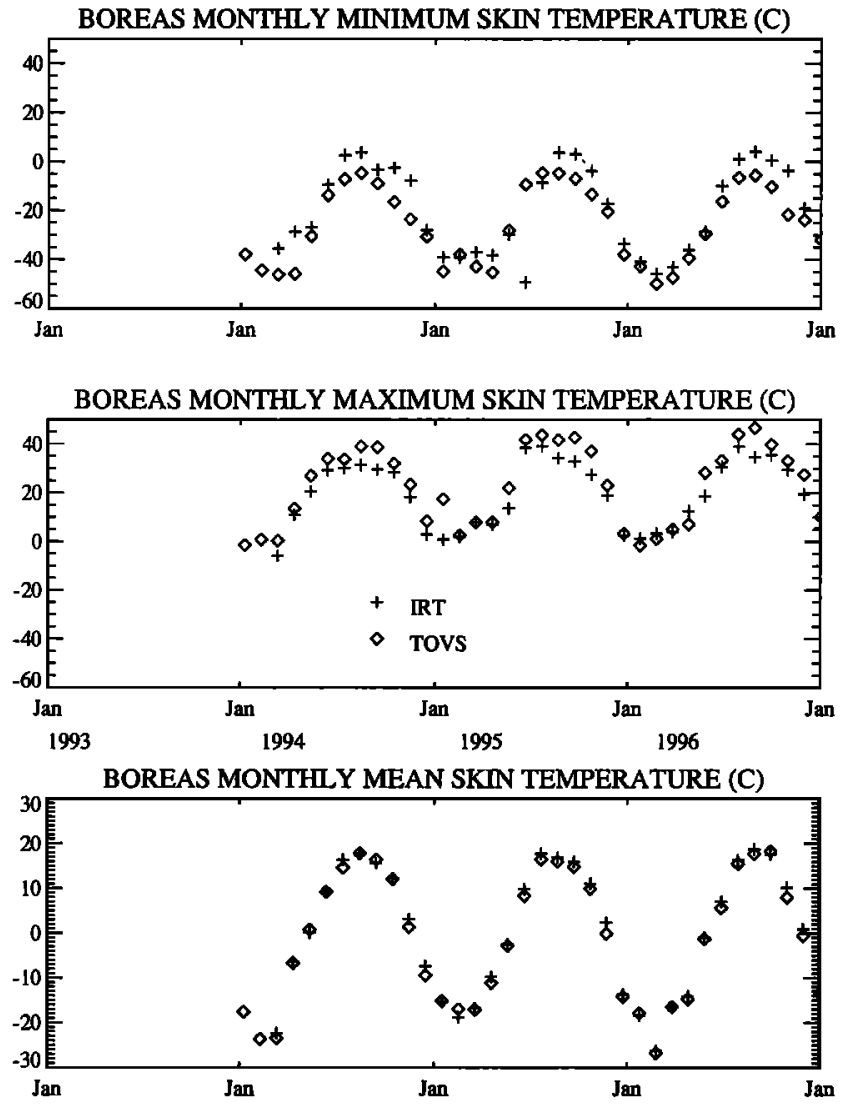

Figure 12. BOREAS-measured and TOVS-retrieved monthly minimum and maximum temperatures. 
Table 5. Seasonal Mean Monthly Comparisons Between BOREAS Ground Observations and TOVS-Retrieved Data for 1994-1996

\begin{tabular}{|c|c|c|c|c|c|c|c|}
\hline \multirow[b]{2}{*}{ Year } & \multirow[b]{2}{*}{ Month } & \multicolumn{2}{|c|}{ Skin Temperature, ${ }^{\circ} \mathrm{C}$} & \multicolumn{2}{|c|}{ Air Temperature, ${ }^{\circ} \mathrm{C}$} & \multicolumn{2}{|c|}{ Vapor Pressure, mbar } \\
\hline & & Ground & TOVS & Ground & TOVS & Ground & TOVS \\
\hline 1994 & 1 & NA & -23.62 & -26.76 & -22.86 & 0.67 & 0.93 \\
\hline 1994 & 2 & -22.07 & -23.46 & -23.86 & -21.87 & 0.71 & 0.96 \\
\hline 1994 & 3 & -6.50 & -6.72 & -6.34 & -5.38 & 2.75 & 2.98 \\
\hline 1994 & 4 & 0.12 & 0.79 & -0.84 & 0.31 & 3.12 & 4.06 \\
\hline 1994 & 5 & 8.56 & 9.22 & 7.69 & 10.23 & 6.21 & 8.22 \\
\hline 1994 & 6 & 15.70 & 14.61 & 14.65 & 16.05 & 9.24 & 11.74 \\
\hline 1994 & 7 & 17.04 & 17.82 & 16.05 & 19.30 & 11.79 & 12.39 \\
\hline 1994 & 8 & 15.45 & 16.42 & 14.39 & 17.27 & 10.81 & 11.22 \\
\hline 1994 & 9 & 12.51 & 12.04 & 11.57 & 13.78 & 9.02 & 9.24 \\
\hline 1994 & 10 & 3.86 & 1.35 & 3.25 & 3.98 & 6.04 & 5.54 \\
\hline 1994 & 11 & -7.67 & -9.41 & -8.05 & -8.12 & 3.13 & 2.65 \\
\hline 1994 & 12 & -15.38 & -15.16 & -15.59 & -12.76 & 1.91 & 1.91 \\
\hline 1995 & 1 & -17.90 & -16.98 & -17.97 & -15.10 & 1.45 & 1.51 \\
\hline 1995 & 2 & -17.12 & -17.12 & -17.22 & -15.38 & 1.45 & 1.64 \\
\hline 1995 & 3 & -9.24 & -11.15 & -9.68 & -7.91 & 2.76 & 2.70 \\
\hline 1995 & 4 & -2.75 & -2.83 & -3.02 & -0.86 & 3.22 & 3.96 \\
\hline 1995 & 5 & 8.68 & 8.34 & 7.79 & 8.97 & 5.22 & 8.04 \\
\hline 1995 & 6 & 16.97 & 16.48 & 16.23 & 17.26 & 10.87 & 13.25 \\
\hline 1995 & 7 & 16.09 & 15.98 & 15.07 & 17.71 & 11.42 & 12.70 \\
\hline 1995 & 8 & 15.64 & 14.80 & 14.67 & 16.83 & 12.61 & 11.62 \\
\hline 1995 & 9 & 10.78 & 9.91 & 9.92 & 11.23 & 8.23 & 8.94 \\
\hline 1995 & 10 & 2.45 & -0.13 & 1.79 & 1.74 & 5.93 & 5.22 \\
\hline 1995 & 11 & -13.40 & -14.21 & -13.78 & -12.33 & 1.98 & 2.00 \\
\hline 1995 & 12 & -18.42 & -17.89 & -18.57 & -16.23 & 1.55 & 1.59 \\
\hline 1996 & 1 & -26.36 & -26.77 & -26.27 & -24.90 & 0.82 & 0.87 \\
\hline 1996 & 2 & -16.26 & -16.46 & -16.34 & -14.46 & 1.66 & 1.74 \\
\hline 1996 & 3 & -13.99 & -14.76 & -14.30 & -13.57 & 1.55 & 1.63 \\
\hline 1996 & 4 & -1.37 & -1.27 & -1.82 & -0.49 & 3.31 & 3.86 \\
\hline 1996 & 5 & 6.53 & 5.64 & 5.61 & 7.07 & 5.19 & 6.86 \\
\hline 1996 & 6 & 16.00 & 15.51 & 14.99 & 15.92 & 10.79 & 11.87 \\
\hline 1996 & 7 & 18.28 & 17.73 & 17.30 & 18.33 & 12.84 & 12.56 \\
\hline 1996 & 8 & 17.23 & 18.29 & 16.38 & 18.48 & 12.36 & 11.60 \\
\hline 1996 & 9 & 9.82 & 7.98 & 9.05 & 9.73 & 9.18 & 8.37 \\
\hline 1996 & 10 & 0.89 & -0.58 & 0.36 & 0.95 & 5.35 & 5.14 \\
\hline 1996 & 11 & -13.14 & -13.45 & -13.43 & -12.02 & 2.10 & 2.06 \\
\hline 1996 & 12 & NA & NA & NA & NA & NA & NA \\
\hline
\end{tabular}

and minima at the same time of the year and show similar trends. An exception is when the surface skin temperature from TOVS is lower in February 1995 as compared to January 1995 when the ground observations show an opposite trend (warmer in February relative to January). In the case of surface air temperatures the differences between the ground and the satellite mean monthly values are larger. There are differences of the order of $2^{\circ}-4^{\circ} \mathrm{C}$ for the winter months of December, January, and February. The surface air temperature shows a cycle similar to the surface skin temperature. A reason for this could be due to canopy cover which results in close surface skin and air temperatures. The surface air temperatures show good comparisons with a few exceptions. In particular, there is a difference of $4^{\circ} \mathrm{C}$ in January 1994. The surface vapor pressure shows an agreement of 0.5 mbar or better for most of the months. The range of the seasonal cycle is around $12 \mathrm{mbar}$ for all the three years. There are a few cases of differences greater than 1 mbar such as June 1996. The TOVS retrievals capture the seasonal cycle of surface vapor pressure with an accuracy of $0.5-1.0 \mathrm{mb}$. It can be seen that the biases in the case of the seasonal cycle are less than those corresponding to the daily comparisons as seen in Tables 2, 3, and 4. This is an expected reduction due to temporal averaging. This result holds significance for the use of TOVS data for climatological and eco- logical studies which need long-term data sets to monitor vegetation dynamics in response to the surface meteorology.

\section{Discussion and Conclusions}

The aim of this paper has not been to assume that the ground observations are perfect and characterize an "error" in the satellite retrievals. Since satellite sensors and ground-based sensors have different measurement basis, they cannot be directly compared to characterize "errors" in the satellite data. Instead, the statistics of comparisons between the ground-based and the satellite-based values have been examined in detail.

The validation studies of Sugita and Brutsaert [1993], Goetz et al. [1995], Kalluri and Dubayah [1995] were carried out over limited time periods (a few days) and very limited areal extents. A study by Jin et al. [1997] compared the difference between the surface skin and the surface air temperatures simulated by the NCAR CCM2 coupled with the BATS (Biosphere-Atmosphere Transfer Scheme) and those obtained from FIFE observations in an indirect manner. Direct comparisons carried out by Andersen [1997] between surface skin temperatures estimated by the split window technique using AVHRR (advanced very high resolution radiometer) data and ground observations for 40 days in HAPEX-Sahel yielded dif- 
ferences between $-2^{\circ}$ and $3^{\circ} \mathrm{C}$. Xiang and Smith [1997] report an accuracy of $1 \%$ in the surface skin temperature and surface emissivity retrieved from SSM/I (Special Sensor Microwave Imager) over HAPEX-Sahel. Goetz [1997] found an increased correlation between higher spatial resolution remotely sensed data and in situ surface skin temperature at FIFE.

The estimates of standard deviation of the differences between the satellite-retrieved quantities and the ground data obtained in the field campaigns for surface skin temperature, surface air temperature, and surface vapor pressure vary around (with different values for different field campaigns and satellite overpass times, these numbers are our "best" estimates) $4^{\circ} \mathrm{C}, 3.5^{\circ} \mathrm{C}$, and $3.5 \mathrm{mb}$, respectively, with part of these differences being due to sampling errors. The maximum values of these standard deviations are $7.7^{\circ} \mathrm{C}, 5.4^{\circ} \mathrm{C}$, and $4.3 \mathrm{mb}$, respectively, for surface skin, surface air temperatures, and surface vapor pressure. These estimates are based on the three field campaigns: FIFE, HAPEX-Sahel, and BOREAS studied in this paper and summarized in Tables 2, 3, and 4. These difference estimates can be used as initial guesses to data assimilation procedures which assimilate satellite data in land surface models.

Lakshmi and Susskind [1998] compared TOVS-retrieved monthly vapor pressure and air temperature with station observations from four different regions (Abilene, Texas, National Airport, Virginia, Cita and Minsk in the former Soviet Union) across the world. They found a bias of -0.8 to $0.15 \mathrm{~K}$ for the monthly air temperature and $-1.0-0.6$ mbar for these four regions. The slope and coefficient of correlation were close to unity. The standard deviation of the differences between 1.1 and $2.4 \mathrm{~K}$ for air temperature and 1.0 and $2.0 \mathrm{mbar}$ for vapor pressure. The better agreement in this case is due to the use of monthly data which removes the day-to-day variability and hence reduces the difference between the satellite retrievals and ground observations.

The results of this study are parallel to the study by Prince et al. [1998] where the authors estimated differences of the order of $3.5^{\circ} \mathrm{C}$ for surface skin temperature, $3.9^{\circ} \mathrm{C}$ for air temperature and 10.9 mbar for vapor pressure deficit. Their study focused on the same three field campaigns (FIFE, HAPEXSahel, and BOREAS) for the ground-based observations and the AVHRR as the source of satellite data. Sugita and Brutsaert [1993] found that the correlation coefficient was 0.96 and 0.92 and the root mean square error was 2.2 and $3.3 \mathrm{~K}$ for the NOAA 9 and NOAA 10 satellite-retrieved potential surface temperatures compared to FIFE data for 1987. The values for surface air temperature comparisons for BOREAS (as seen in Table 3) can be compared against a similar study of Czajkowski et al. [1997] which compares the air temperature derived from the AVHRR data for the period between April and September 1994 (a total of 228 observations). Their results show a standard deviation of $4.2^{\circ} \mathrm{C}$ and a correlation of 0.8 . The AVHRR data are at a much higher spatial resolution than the TOVS (around $9 \mathrm{~km}^{2}$ compared to $3600 \mathrm{~km}^{2}$ for the TOVS) which contributes to the agreement between the satellite-retrieved and the observations of surface temperatures.

This paper reports the comparison results of the TOVSretrieved land surface variables for a wide range of land surface conditions. We hope that this will provide the scientific community with the proper interpretation of the data in regard to its agreement with field measurements. The data can be used for validation, calibration, and assimilation in land surface hydrological models and long-term climatological and ecological studies. In the future, improved satellite sensors will be able to achieve greater precision, better spatial resolution, and greater temporal sampling (with the availability of multiple satellites).

\section{References}

Andersen, H. S., Land Surface Temperature Estimation based on NOAA-AVHRR data during the HAPEX-Sahel Experiment, $J . \mathrm{Hy}$ drol., 188-189, 788-814, 1997.

Anyamba, E., and J. Susskind, A comparison of TOVS ocean skin and air temperatures with other data sets, J. Geophys. Res., 103, 10,489$10,511,1998$.

Betts, A. K., and J. H. Ball, FIFE surface climate and site-average data set 1987-89, J. Atmos. Sci., 55(7), 1091-1108, 1998.

Czajkowski, K. P., T. Mulhern, S. Goward, J. Cihlar, R. Dubayah, and S. Prince, Biospheric environmental monitoring at BOREAS using AVHRR observations, J. Geophys. Res., 102, 29,651-29,662, 1997.

Goetz, S. J., Multisensor analysis of NDVI, surface temperature, and other biophysical variables at a mixed grassland site, Int. J. Remote Sens., 18, 71-94, 1997.

Goetz, S. J., R. Halthore, F. G. Hall, and B. L. Markham, Surface temperature retrieval in a temperate grassland with multi-resolution sensors, J. Geophys. Res., 100, 25,397-25,410, 1995.

Goutorbe, J.-P., et al., HAPEX-Sahel: A large-scale study of landatmosphere interactions in the semiarid tropics, Ann. Geophys., 12, 53-64, 1994.

Jin, M., R. E. Dickinson, and A. M. Vogelmann, A comparison of CCM2-BATS skin temperature and surface-air temperature with satellite and surface observations, J. Clim., 10, 1505-1524, 1997.

Kalluri, S. N., and R. O. Dubayah, Comparison of atmospheric correction models for thermal bands of the advanced very high resolution radiometer over FIFE, J. Geophys. Res., 100, 25,411-25,418, 1995.

Kidwell, K. B. (Ed), NOAA Polar Orbiter Data Users Guide (TIROS-N, NOAA-6, NOAA-7, NOAA-8, NOAA-9, NOAA-10, NOAA-11, NOAA-12, NOAA-13 and NOAA-14), NOAA/NESDIS, Natl. Clim. Data Cent., Washington, D. C., 1995.

Lakshmi, V., and J. Susskind, Determination of land surface skin temperatures and surface air temperature and humidity from TOVS HIRS2/MSU data, Adv. Space Res., 22(5), 629-636, 1998.

Prince, S. D., et al., Geographical, biological and remote sensing aspects of the Hydrologic Atmospheric Pilot Experiment in the Sahel (HAPEX-Sahel), Remote Sens. Environ., 51, 215-234, 1995.

Prince, S. D., S. J. Goetz, R. O. Dubayah, K. P. Czajkowski, and M. Thawley, Inference of surface and air temperature, atmospheric precipitable water and vapor pressure deficit using AVHRR satellite observations: Validation of algorithms, J. Hydrol., 212-213, 230-250, 1998.

Sellers, P. J., and F. G. Hall, FIFE in 1992: Results, scientific gains, and future research directions, J. Geophys. Res., 97, 19,091-19,109, 1992.

Sellers, P. J., F. G. Hall, G. Asrar, D. E. Strebel, and R. E. Murphy, An overview of the First International Satellite Land Surface Climatology Project (ISLSCP) Field Experiment (FIFE), J. Geophys. Res., 97, 18,345-18,371, 1992.

Sellers, P. J., et al., BOREAS in 1997: Experimental overview, scientific results, and future directions, J. Geophys. Res., 102, 28,73128,769, 1997.

Sugita, M., and W. Brutsaert, Comparison of land surface temperatures derived from satellite observations with ground truth during FIFE, Int. J. Remote Sens., 14, 1659-1676, 1993.

Susskind, J., J. Rosenfield, and D. Reuter, Remote sensing of weather and climate parameters from HIRS2/MSU on TIROS-N, J. Geophys. Res., 89, 4677-4697, 1984.

Susskind, J., P. Piraino, L. Rokke, L. Iredell, and A. Mehta, Characteristics of the TOVS Pathfinder Path A data set, Bull. Am. Meteorol. Soc., 78(7), 1449-1472, 1997.

Xiang, X., and E. A. Smith, Feasibility of simultaneous surface temperature-emissivity retrieval using SSM/I measurements from HAPEX-Sahel, J. Hydrol., 188-189, 330-360, 1997.

V. Lakshmi and J. Susskind, Department of Geological Sciences, University of South Carolina, Columbia, SC 29208. (vlakshmi@ geol.sc.edu)

(Received March 12, 1999; revised August 12, 1999; accepted August 17, 1999.) 